This is the peer reviewed version of the following article: Mason THE, Keane A, Redpath SM, Bunnefeld N. The changing environment of conservation conflict: Geese and farming in Scotland. Journal of Applied Ecology 2018;55:651-662, which has been published in final form at https://doi.org/10.1111/1365-2664.12969. This article may be used for noncommercial purposes in accordance With Wiley Terms and Conditions for selfarchiving. 


\section{The changing environment of conservation conflict: geese and farming in}

\section{Scotland}

3 Authors: Tom H.E. Mason ${ }^{1}$, Aidan Keane ${ }^{2}$, Stephen M. Redpath ${ }^{3}$ and Nils Bunnefeld ${ }^{1}$.

4 Affiliations: ${ }^{1}$ Biological and Environmental Sciences, Faculty of Natural Sciences, University of

5 Stirling, Stirling, FK9 4LA, UK; ${ }^{2}$ School of Geosciences, University of Edinburgh, Edinburgh, EH9

$6 \quad 3 \mathrm{FF}, \mathrm{UK} ;{ }^{3}$ Institute of Biological and Environmental Sciences, University of Aberdeen, Tillydrone

7 Avenue, Aberdeen AB24 2TZ, UK.

8 Corresponding author: Tom H.E. Mason, Biological and Environmental Sciences, Faculty of

9 Natural Sciences, University of Stirling, Stirling, FK9 4LA, UK. Email: tom.h.e.mason@gmail.com

10 Running title: Environmental change and conservation conflict

11 Word count: 7,457

12 Number of tables: 2

13 Number of figures: 7

14 Number of references: 47 
1. Conflict between conservation objectives and human livelihoods is ubiquitous and can be highly damaging, but the processes generating it are poorly understood. Ecological elements are central to conservation conflict, and changes in their dynamics - for instance due to anthropogenic environmental change - are likely to influence the emergence of serious human-wildlife impacts and, consequently, social conflict.

2. We used mixed-effects models to examine the drivers of historic spatio-temporal dynamics in numbers of Greenland barnacle geese (Branta leucopsis) on the Scottish island of Islay to identify the ecological processes that have shaped the environment in which conflict between goose conservation and agriculture has been triggered.

3. Barnacle goose numbers on Islay increased from 20,000 to 43,000 between the $1987 / 88$ and 2015/16 seasons. Over the same period, the area of improved grassland increased, the number of sheep decreased and the climate warmed.

4. Goose population growth was strongly linked to the increasing area of improved grassland, which provided geese with more high quality forage. Changing climatic conditions, particularly warming temperatures on Islay and breeding grounds in Greenland, have also boosted goose numbers.

5. As the goose population has grown, farms have supported geese more frequently and in larger numbers, with subsequent damaging effects. The creation of high-quality grassland appears to have largely driven damage by geese. Our analysis also reveals the drivers of spatial variation in goose impacts: geese were more likely to occur on farms closer to roosts and those with more improved grassland. As geese numbers have increased they have spread to previously less favoured farms.

6. Synthesis and applications. Our study demonstrates the primary role of habitat modification in the emergence of conflict between goose conservation and agriculture, alongside a secondary role of climate change. Our research illustrates the value of exploring socioecological history to understand the processes leading to conservation conflict. In doing so, we identify those elements that are more controllable, such as local habitat management, and 
less controllable, such as climate change, but which both need to be taken into account when managing conservation conflict.

Keywords: barnacle geese, climate change, conservation conflict, goose conservation conflict, grass damage, habitat modification, human-wildlife conflict, Islay, population dynamics, spatial ecology

\section{INTRODUCTION}

Conservation conflict - conflict between stakeholders representing biodiversity conservation and those representing other interests (e.g. food production) - is widespread globally (Redpath et al. 2013, 2015). Such conflict can be highly damaging to both biodiversity and livelihoods, so represents a key challenge for society (Sillero-Zubiri, Sukumar \& Treves 2007). Human-wildlife conflict researchers have often focused on quantifying the negative impacts of wildlife on humans and vice-versa (Woodroffe, Thirgood \& Rabinowitz 2005). In contrast, research into the processes leading to the emergence of serious impacts and, in turn, conflict between stakeholders, is currently scarce (Young et al. 2010). Such research could provide new insight into why conflict emerges and how it can be managed.

While conflict is clearly a social phenomenon, it emerges from environments comprising both socio-economic and natural elements, and can be triggered by change in any of these, such as wildlife population growth or decreases in the market values of crops, if they result in impacts perceived to be unacceptable by one or more parties (Young et al. 2010). In particular, ecological elements (e.g., species, ecosystems) are central to conflicts, but such ecological temporal dynamics tend to be studied in isolation rather than in interaction with human activities (Redpath \& Sutherland 2015). Encouragingly, conflict studies are starting to combine ecological and human dynamics over short time-scales (e.g., Simonsen et al. 2016). Historic applied ecological data represents a potentially valuable resource for studying how environmental change has contributed to the development of conservation conflicts, by revealing how historic management and natural resource use by humans have shaped the ecological context of conflict (Lambert 2015). 
The analysis of spatial historic data could additionally reveal why conflict is more likely to emerge in certain areas. The potential for conflict varies considerably due to spatial variation in social, economic and ecological factors (White et al. 2009). The latter can play a prominent role, for instance by influencing the severity of negative impacts of wildlife experienced by humans. For example, livestock depredation by wild carnivores can be more frequent in areas with more favourable habitat for wild prey, leading to a greater potential for conflict (Treves et al. 2004). Such spatial variation is often highly skewed, with only a small proportion of stakeholders experiencing serious negative consequences (Naughton-Treves 1998; Michalski et al. 2006). In this case, only farms located within large wilderness areas may experience high rates of livestock depredation (Michalski et al. 2006). Approaches based on spatial historic data could reveal how these skewed spatial patterns have evolved, and how they may lead to conflict in the future.

Here, we used 29-year and 18-year ecological time-series to examine how environmental change has contributed to the emergence of conflict over the conservation of Greenland barnacle geese (Branta leucopsis) and agriculture on the Scottish island of Islay. Migratory waterbird populations are regarded as a high conservation priority due to their strong reliance on restricted sites along their migration routes; environmental change at a single site can negatively impact an entire population (Kirby et al. 2008). Indeed, Greenland barnacle geese are an Annex I species on the European Union (EU) Birds Directive. Islay is an important site for this species, supporting more than half of the world's population during the non-breeding season $(56 \%$ of 81,000 in 2013 ; Mitchell \& Hall 2013). Birds arrive in early October from breeding grounds in eastern Greenland, via staging grounds in Iceland, and leave Islay by mid-April (Fig. 1a). Many goose populations are growing throughout the northern hemisphere, and are feeding increasingly in agricultural rather than natural habitats (e.g., Gauthier et al. 2005; Van Eerden et al. 2005), causing substantial economic damage to grassland and arable crops (Owen 1990). In such areas, conflict between conservationists and farming bodies is common (Fox et al. 2016). This is the case on Islay, where barnacle geese feed predominantly on farmed grassland and form large flocks that cause substantial damage to grass yields (Percival \& Houston 1992). Barnacle goose numbers on Islay more than doubled from around 

stakeholders, including conservation groups, farmers and the governmental organisation in charge of goose management, Scottish Natural Heritage (SNH; McKenzie \& Shaw 2017). To date, management of goose conservation-agriculture conflict on Islay and elsewhere has generally focused on reducing agricultural damage caused by geese. Coordinated approaches combining habitat management of goose refuges, scaring geese from agricultural areas, and payment of compensation to farmers experiencing grass and crop damage have seen some success in areas such as the Netherlands, Norway and Sweden (Cope, Vickery \& Rowcliffe 2005; Fox et al. 2016). However, increasing goose numbers can outstrip both the size of refuges and the level of funding for compensation, necessitating population regulation through sport hunting (Madsen et al. 2017) or, more controversially, culling, as has been applied on Islay (McKenzie \& Shaw 2017).

To understand how the environment has shaped the conflict over time, we investigated the drivers of increasing goose numbers on Islay, at two spatial scales. First, we examined the factors that have driven increases in total barnacle goose abundance on Islay (hereafter, 'population-scale analysis'), relating goose numbers to historic land-use and climate data for Islay and breeding grounds

112 in Greenland. Increasing goose numbers across North America and western Europe are thought to 113 have been caused by a combination of agricultural intensification (e.g., Van Eerden et al. 2005), release from hunting pressure (Menu, Gauthier \& Reed 2002) and climate change, such as warming temperatures (e.g., Gauthier et al. 2005), though the relative importance of these drivers is unclear and likely to vary among species and regions. Here, we tested four non-mutually exclusive hypotheses for population increases, assuming that effects would act primarily via increasing forage availability and/or quality. We tested whether population increases resulted from:

1. Increases in improved grassland availability on Islay following agricultural improvements

2. Increases in improved grassland availability on Islay due to reductions in sheep densities

3. Warming and drying climate on Islay

4. Warming and drying climate at breeding grounds in Greenland 
We then examined how changes in goose abundance have influenced the distribution of geese across

124 different farms, (hereafter, 'farm-scale analysis'), testing three hypotheses. We tested whether geese

125 occurred more frequently and in greater numbers:

7. On farms closer to roosting sites

130 MATERIALS AND METHODS

131 Study area

132 Islay is an island of 62,000ha situated in the Inner Hebrides of western Scotland (Fig. 1). Islay's

133 landscape is dominated by agriculture (56,000ha), predominantly rough grazing and farmed grassland 134 supporting sheep and cattle. In 1992, a government-funded goose management scheme was initiated on Islay, partially compensating farmers for economic losses from goose damage. From 2000, farmers were also allowed to protect parts of their farm by scaring geese, which in certain cases included

137 licensed shooting of geese. However, steep increases in goose numbers during the early 2000s, combined with growing costs of farming and reductions in funding for compensation, resulted in geese causing serious economic damage to Islay’s agricultural economy (currently estimated at $£ 1.6$ million per annum). In 2014, a new goose management strategy was implemented by SNH and the

141 Scottish Government, which aimed to reduce goose damage by $25-30 \%$ by reducing barnacle goose numbers (SNH 2014). Since 2014, between 1,000 and 2,700 barnacle geese have been culled on Islay each year. This has contributed to an escalation in conflict between $\mathrm{SNH}$, farmers and conservation organisations on Islay, with the Royal Society for the Protection of Birds and Wildfowl and Wetlands

145 Trust lodging a formal complaint to the European Commission in 2015 over the culling programme. 
Population censuses across the wintering range of Greenland barnacle geese are undertaken every five years, using ground and aerial surveys (Mitchell \& Hall 2013). More frequent surveys are undertaken at a number of key wintering sites, including Islay. We used data from island-wide ground surveys of Islay's overwintering barnacle geese, carried out by SNH multiple times each year, generally in November, December, January and March $(n=101)$. These provided estimates of total goose numbers on Islay for the period 1987-2016 and farm-specific goose numbers for the period 1998-2016. Surveys were conducted twice over consecutive days and averaged to produce a more reliable estimate of total barnacle goose abundance. They were carried out by five pairs of trained surveyors in vehicles around five pre-defined routes of sub-areas of Islay and were conducted simultaneously on each route, with care taken to avoid double counting both within and among sub-areas by monitoring the movements of flocks during surveys. Geese were counted from vehicles using binoculars and spotting scopes, at distances of $20 \mathrm{~m}-2 \mathrm{~km}$. The farms occupied by geese were recorded according to a system of unique field codes, using maps of the study area.

Population-scale analysis

To test hypotheses 1-4, we acquired land-use and climate data for the period 1985-2015. We obtained Islay land-use data from

the Scottish Government (http://www.gov.scot/Topics/Statistics/Browse/Agriculture-Fisheries/Datasets). We used data on annual variation in sheep numbers on Islay, collected by the annual June Scottish Agricultural census, and in the area of improved grassland on Islay (defined as grassland that has previously been reseeded), collected by the Agricultural census (1985-2008) and from Single Farm Application forms (2009-2015). We used monthly climate data for the West Scotland from the Met Office to represent Islay's climate (http://www.metoffice.gov.uk/climate/uk/summaries/datasets), calculating mean daily temperature and total precipitation during the barnacle goose non-breeding season (October-March). We used monthly climate data from Danmarkshavn meteorological station, which lies within the barnacle goose breeding range in eastern Greenland $\left(74.48^{\circ} \mathrm{N} ; 18.98^{\circ} \mathrm{W}\right)$, to represent breeding 
ground climate (http://research.dmi.dk/publications/other-publications/reports/). We calculated mean daily temperature and total precipitation for two important periods during breeding for arctic goose reproduction and post-fledging survival (e.g., Dickey, Gauthier \& Cadieux 2008): in early spring (May) when geese have recently arrived and are egg laying, and late summer (August) when geese are brood rearing and preparing to leave. We considered predictors at time-lags of 1-3 years, assuming that predictors would influence abundance via lagged, and possibly additive, effects on survival and recruitment. Time-lags of $t-1$ represent, for Greenland, the climate during the breeding season directly preceding abundance surveys on Islay and, for Islay, the climate/land-use during the previous year's non-breeding season on Islay. Greenland $t_{t-3}$ and Islay $y_{t-2}$ predictors allow for delayed cohort effects on the future reproduction of juveniles, which reach sexual maturity at 2 years (Forslund \& Larsson 1992; see Fig. S1 in Supporting Information for an illustration of the timing of predictors). Environmental conditions experienced in early life by arctic-breeding geese can influence survival (van der Jeugd \& Larsson 1998) and reproduction in later life (Sedinger, Flint \& Lindberg 1995). See Table 1 for a summary of all predictors and their hypothesised effects.

We fitted linear mixed-effects regressions between barnacle goose abundance and predictors, including a random intercept for survey month, using the 'lme' function in R (Pinheiro et al. 2016; R Core Team 2016). We fitted models with maximum likelihood and scaled variables to produce standardised coefficients. We considered separate improved grassland coefficients for pre-2009 and post-2009 time-periods, using an interaction with a categorical variable representing time-period. This was because, whilst improved grassland is defined in the same way on the data collection forms for these periods, more guidance on differences between improved grassland and rough grazing is provided on Single Farm Application Forms (post-2009), resulting in slightly different classifications of improved grassland between the two periods (Fig. 2b). We fitted models with 'AR-1' autocorrelation structures to account for temporal autocorrelation in model residuals. We considered models of increasing complexity, fitting models containing all possible combinations of predictors for Islay land-use, Islay climate and Greenland climate (Table 1) for a given number of predictors, until the addition of an extra predictor did not produce a parsimonious model according to Akaike's 
Information Criterion (AIC). We assessed models with $\triangle \mathrm{AIC} \leq 6$ and lower than simpler nested models to have some support (Richards 2015), and considered predictors occurring in all these 'top models' to have strong support. We visualised relationships between goose abundance and these predictors using partial-effect plots, which display response-predictor relationships while accounting statistically for the effects of other predictors in a model. This is done by plotting $\mathrm{r}$ (xlother predictors) against $\mathrm{r}$ (ylother predictors), where $\mathrm{r}(x$ lothers) are residuals of a model regressing predictor $x$ against all other predictors (but not response $y$ ) and $\mathrm{r}$ (ylothers) are residuals of a model regressing $y$ against all predictors except for $x$.

Farm-scale analysis

To test hypotheses 5-7, we fitted models exploring the influences of Islay goose abundance, farmspecific improved grassland area and farm-specific distance to nearest roost on barnacle goose numbers on farms. To test the effect of abundance, we used the total abundance estimates corresponding to farm-scale goose numbers. We calculated distance to roost as the Euclidean distance between a farm's centroid and the nearest barnacle goose roost. There are three main night-time roosting sites on Islay, composed predominantly of saltmarsh and inter-tidal mudflats, used by the majority of barnacle geese (see Fig. 1b). We calculated mean area of improved grassland (grassland reseeded within the past seven years) on farms using data provided by the Islay goose management scheme. See Table 1 for a summary of these predictors.

We used a hurdle modelling procedure, first fitting models exploring drivers of probability of goose occurrence during a survey on farms, using presence-absence data (hereafter, 'occurrence models'), and second fitting models exploring the drivers of their numbers when they were present, using presence-only count data (hereafter, 'count models'). This procedure allowed us to investigate the processes generating goose occurrence and numbers separately. We fitted models using linear mixed-effects regressions, including random intercepts for survey year and farm ID ( $n=103)$ using the 'glmer' function in R (Bates et al. 2015). We fitted models with maximum likelihood, using binomial and Poisson error structures for occurrence and count models, respectively. We tested for spatial autocorrelation per survey in the responses and residuals by calculating Moran's $I$ statistic, to determine the ability of models to explain any spatial autocorrelation in the responses. There were low 
levels of autocorrelation in the data, with significant spatial autocorrelation in farm-specific occurrences and counts, respectively, on only 18\% (21/120) and 5\% (6/120) of surveys. There were similarly low levels of autocorrelation in the residuals of the best occurrence (16\%) and count models $(4 \%)$.

To test hypothesis 5 , we first fitted models with total barnacle goose abundance as a fixed effect. We included farm ID random coefficients for the effect of abundance, to account for variation in this effect among farms. We included linear and quadratic effects of day of year to account for seasonal changes in goose spatial aggregation potentially resulting from depletion in grass availability. We fitted models with the scaled predictors together, separately and both absent, identifying the best model using AIC. Next, to test hypotheses 6 and 7, we extracted the farm-specific intercepts/coefficients (i.e., $\beta_{\text {ropulation }}+\gamma_{\mathrm{ram}}$ ) from the best models, and fitted post-hoc models exploring the effects of improved grassland area and distance to roost on variation among farms in i) goose occurrence/number (farm-specific intercepts) and ii) the effect of Islay abundance on occurrence/number (farm-specific coeffcients). We used non-linear regression, implemented with the 'nlsLM' function in R (Elzhov et al. 2013), considering linear and curvilinear effects of the form $a \mathrm{x}^{b}$ for each scaled predictor. As before, we selected the best models using AIC.

For all models, we assessed model fit using $R^{2}$ (Nakagawa \& Schielzeth 2013) and collinearity using variance inflation factors, accepting those $<3$ (Zuur, Ieno \& Elphick 2010).

\section{RESULTS}

\section{Population-scale analysis}

The best model of barnacle goose abundance $\left(R^{2}=0.86\right)$ showed that population increases were linked primarily to changes in land-use on Islay, but were also associated with climate variation on Islay and Greenland (Fig. 3-4). All top models contained predictors of Islay land-use, Islay climate and Greenland climate (Fig. 3; Table S1). The area of improved grassland on Islay two years previously was by far the strongest predictor of goose abundance (Fig. $3 \& 4$ a); this predictor was selected in all top models and its partial effect $\left(R^{2}=0.67\right)$ was more than four times stronger than any other. This supports hypothesis 1 , suggesting that the area of improved grassland on Islay - which increased by 
45\% between 1987 and 2004 (Fig. 2b) - has boosted goose numbers by roughly 6,000 per 1,000ha increase in grassland. In contrast, there was no evidence for hypothesis 2 - a negative effect of sheep numbers - despite a 40\% decrease in sheep numbers on Islay from 78,500 to 47,000 between 1998 and 2011 (Fig. 2c).

We found strong evidence for a positive effect of Islay temperature on abundance, operating at both one and two year time-lags, thus supporting hypothesis 3 (Fig. $3 \& 4 \mathrm{~b}$ ). Both time-lags were present in all top models (Fig. 3), with a $1^{\circ} \mathrm{C}$ increase at a one year time-lag boosting goose numbers by roughly 3,000 . We also detected weaker, negative effects of Islay precipitation at one and two year time-lags, with goose numbers decreasing by $700\left(t_{1}\right)$ and $900\left(t_{2}\right)$ per $100 \mathrm{~mm}$ increase in precipitation. Both time-lags featured in the best model, but not all top models (Fig. 3; Table S1). Islay's October-March temperature and precipitation exhibited increasing, though non-significant, trends during the study period (see Fig. S2). Spring and late summer climatic conditions at breeding grounds were also associated with goose abundance, providing some support for hypothesis 4 , although effect sizes were generally weaker than for Islay climate (Fig. $3 \& 4$ c). There was evidence for a moderate positive effect of August temperature $\left(2,300\right.$ more geese per $1^{\circ} \mathrm{C}$ increase) and a weaker negative effect of August precipitation (1,100 fewer geese per $10 \mathrm{~mm}$ increase) during the breeding season directly preceding goose surveys; these effects are present in all top models. A weak negative effect of precipitation at a two year time-lag was also present in all top models. These effects indicate that warmer and drier periods preceding migration from breeding grounds influenced recruitment positively. August breeding ground temperatures have become significantly warmer, from an average of $2.2^{\circ} \mathrm{C}$ in 1985 to $3.6^{\circ} \mathrm{C}$ in 2015 , but there has been no significant change in precipitation (see Fig. S2). There was some evidence of positive effects of spring breeding ground precipitation and temperature on goose abundance (Fig. 3; Table S1), in particular suggesting delayed positive effects of wet springs on recruitment. However these effects were not present in all top models (Fig. 3; Table S1). 
282 The best models describing the number and occurrence probability of geese at a farm level contained 283 positive effects of goose abundance, thus supporting hypothesis 5 (Fig. 5; Table S2). Our models estimated that, for a $10 \%$ growth in the population, probability of occurrence and abundance on an average farm increased by $5 \%$ and $9 \%$, respectively. The best models also contained quadratic effects of day (Table S2). The probability of goose occurrence on farms increased from the start of the season, peaking in February-March before declining later in the season (see Fig. S3). In contrast, the number of geese recorded per farm showed a slight decline during the season, suggesting that geese spread out over more farms.

Variation in farm-specific intercepts from both occurrence and count models was linked primarily to the area of improved grassland on farms, thus supporting hypothesis 6 . Geese were more likely to occur and to do so in greater numbers on farms with more improved grassland (Fig. 6a \& c; Table 2a). For example, geese were present on farms with 10 ha and 100 ha of improved grassland, respectively, during $7 \%$ and $79 \%$ of surveys, at average abundances of 160 and 1,400 . There was also evidence for negative effects of distance to roost in both models, indicating that geese were more likely to occur and to do so in greater numbers on farms nearer roosts, thus supporting hypothesis 7 (Fig. $6 \mathrm{~b} \& \mathrm{~d}$; Table 2a). For example, geese were present on farms $1 \mathrm{~km}$ and $8 \mathrm{~km}$ from roosts, respectively, during $43 \%$ and $23 \%$ of surveys, at average abundances of 580 and 190 .

While the effect of Islay goose abundance on farm-scale goose occurrence and number was positive on average, it varied in strength and direction among different farms when random effects are considered (Fig. 7). In the best occurrence model, 2 out of the 104 farms had negative abundance coefficients - indicating decreasing occurrence probability as total abundance has increased - whilst for the remaining 98\%, positive coefficients varied considerably, between 0.12 and 2.47 (mean, 1.16).

304 Even greater variation was present in the count model where $21 \%$ of farms have negative abundance coefficients and the remaining $79 \%$ vary by several orders of magnitude, between 0.09 and 11.65 (mean, 2.00). We were able to identify the drivers of farm-specific variation for occurrence models, but not count models. We detected a negative effect of improved grassland area and a positive 
curvilinear effect of distance to roost on farm-specific abundance coefficients for occurrence

309 probability (Table $2 \mathrm{~b}$ ). This suggests that goose occurrence became more likely on farms with less

310 improved grassland and those further from roosts, as goose abundance increased (Fig. 7).

\section{DISCUSSION}

313 This study illustrates how environmental change can shape the ecological dynamics underlying the 314 emergence of conservation conflict. The growth of Islay's barnacle goose population was strongly 315 linked to changing farming practice, specifically improvements to grassland, and was also associated 316 with climate warming. As goose abundance increased, farmers experienced geese on their farms with greater frequency and in larger numbers, and geese spread to previously less favoured farms. By revealing the drivers of goose numbers experienced by farmers, our analysis explained how spatial

319 patterns of human-wildlife impacts can evolve.

\section{Drivers of goose population dynamics}

Increases in the number of barnacle geese on Islay were associated with environmental conditions at different stages of this species' annual cycle. We identified lagged effects of land-cover and climate experienced during the non-breeding season on Islay and of climate experienced during the breeding season on Greenland. Of these, the strongest driver of abundance was the area of improved grassland on Islay. This concurs with other studies implicating agricultural intensification as a likely driver of increasing goose populations (e.g., Abraham, Jefferies \& Alisauskas 2005; Fox et al. 2005). Increased application of Nitrogen-based fertilisers during the $20^{\text {th }}$ century, in Europe encouraged by production subsidies paid through the Common Agricultural Policy until 2003, has created areas of pasture significantly higher in protein and digestibility than natural goose foraging areas (van Eerden et al. 2005). On Islay, some of the increases in high-quality grassland were driven by the EU funded Agricultural Development Programme for the Scottish islands, which commenced in 1987 (McKenzie \& Shaw 2017). The increase in improved grassland has probably increased Islay's goose carrying capacity, providing geese with 'escape' from density-dependent survival. Density-dependence may

334 have acted in recent years, with goose numbers fluctuating around 40,000 and increases in improved 
grassland slowing. Goose abundance correlated most strongly with improved grassland at a two-year 336 time-lag, suggesting that cohort effects may also be acting on survival and reproduction. Cohorts born 337 prior to non-breeding seasons when improved grassland is abundant may produce more offspring when they breed for the first time two years later. Increased immigration from neighbouring nonbreeding sites could also be playing a role in population growth in Islay. However, populations have also increased at neighbouring sites and the total population overwintering on Islay has remained constant during the period of population increase (WWT range-wide surveys: 1999, 0.65; 2003, 0.65; 2008, 0.64; Mitchell \& Hall 2013), suggesting that a strong role of immigration is unlikely.

We identified secondary climatic effects on goose abundance. In particular, abundance was higher following warmer and drier non-breeding seasons. This is probably linked to effects on forage trampling by geese damaging grass (Kahl \& Samson 1984). We detected positive effects of warm and dry weather during the early and late breeding season on Greenland. In particular, abundance was higher following warmer, drier Augusts. Cold, potentially snowy, periods late in the breeding season can result in brood losses due to hypothermia (Dickey, Gauthier \& Cadieux 2008). The presence of climate effects reveals that external, uncontrollable, factors can play a role in shaping the environmental context of conflicts.

We detected no effect of decreasing competition with sheep on goose abundance, though it is possible that such an effect would only acted during the latter part of the study period - when sheep numbers decreased dramatically - and was not detected as a result. Prior to 1998, there was an increasing trend in sheep numbers, largely matching the trend in improved grassland. Another potential driver of abundance increases is the implementation of stricter population protection and subsequent reductions in hunting. However, the protection of barnacle geese by the EU's 1979 Bird's Directive and the UK's 1981 Wildlife and Countryside Act occurred a number of years prior to this study's time-period. Any population recovery would likely be evident for only a short period 
following cessation of hunting, as has been shown for other goose species (Fox et al. 2005; Gauthier et al. 2005).

\section{Drivers of farm-scale goose dynamics}

364 As the population has grown, goose numbers on farms have increased and their distribution has

365 spread over a wider area. These relationships provide a link between the drivers of goose population 366 dynamics and their spatial dynamics at a scale experienced by stakeholders. The creation of highquality grassland was the principal driver of goose population growth and was thus likely to be responsible for the problem of serious grass damage by geese (relationships between local goose abundance and damage are probably simple; Fox et al. 2016).

The farm-specific intercept models also reveal that farms with more improved grassland were more likely to support large numbers of geese, supporting the population-scale results. Such farms are likely to have larger carrying capacities. Additionally, geese are known to graze more intensely on more productive pasture (e.g., Ydenberg \& Prins 1981). Geese were also more likely to occur on farms closer to roosts. In order to minimize energy expenditure, geese preferentially forage closest to roosts and only move further afield when these resources become depleted, as has been identified in a range of goose species including barnacle geese ( $\mathrm{Si}$ et al. 2011). These results go some way in explaining why goose impacts vary between farmers and illustrate how skewed impacts on stakeholders - a common feature of conservation conflicts (e.g., Naughton-Treves 1998; Cope, Vickery \& Rowcliffe 2005) - can emerge. It should be noted that, while the occurrence model explained a large proportion of variation in farm-specific intercepts $\left(R^{2}=0.69\right)$, the count model explained much less $\left(R^{2}=0.09\right)$. There are likely to be a range of other factors contributing to variation in goose numbers among farms, such as scaring intensity and the quality of grassland. abundance on farm-scale goose occurrence and number were highly variable. Interestingly, farms with less improved grassland and further from roosts - which were less likely to support geese on average - became more likely to harbour geese as the population increased. This could be because forage is becoming more depleted on preferred farms, forcing geese to forage more frequently on 
farms further from roosts and those with less improved grassland. As a result, a wider range of farms

389 may have experienced goose damage as the population has grown.

\section{Linking drivers of ecological dynamics to management of conflict}

391 By exploring the socio-ecological history of this conflict, we identified that the contemporary problem

392 of damage to grass by geese on Islay is largely an unforeseen consequence of historic improvements

393 in grass productivity. This illustrates that changes in land management by humans can be a key driver

394 of environmental change contributing to the emergence of conflict. While conservationists have often expressed concern over the negative impacts of agricultural intensification on biodiversity and wildlife populations (e.g., Donald, Green \& Heath 2001), our study illustrates how inadvertent positive impacts of agricultural management on wildlife populations can ultimately be damaging for conservation interests. Proactive responses to initial population increases could prevent humanwildlife impacts from reaching conflict levels and be more cost-effective than reactive interventions (Drechsler, Eppink \& Wätzold 2011). Managers need to tackle emerging conflicts early not only to prevent stakeholders positions from becoming entrenched, for example by working closely with stakeholders to find shared solutions as carried out for geese in Norway and Denmark (Tombre, Eythórsson \& Madsen 2013), but also to prevent impacts from wildlife reaching levels that are challenging and costly to manage.

We found that uncontrollable external processes such as climate change can influence the management strategy evaluation (MSE), an approach gaining popularity in conservation (Bunnefeld, Hoshino \& Milner-Gulland 2011). MSE combines models of natural dynamics with those for monitoring and management, incorporating the various uncertainties of complex socio-ecological systems. The use of shooting as a population-reduction tool on Islay has resulted in the escalation in conflict between stakeholder groups. An alternative strategy could be coordinated reductions in

413 grassland productivity, through decreased reseeding frequencies and fertiliser application, in order to 414 reduce the carrying capacity of the island. The effectiveness of these strategies could depend on 
415 climate, for example if reductions in goose numbers from culling were offset by increases in 416 recruitment due to milder breeding conditions. Using MSE it would be possible to take into account

417 the influence of climate change on the effectiveness of these competing management strategies.

The gathering of ecological and social evidence is recognised as an important step along the

419 roadmap to conflict management (Redpath et al. 2013). However, in many cases, management 420 interventions are put in place before the drivers of conflict are fully understood. The suitability of 421 different management options will depend on the unique ecological and socio-economic characteristics of a particular region (Henle et al. 2008), including historic changes in these characteristics (Lambert 2015). As such, studies like ours provide an important step in understanding

424 how conflict emerges and how to manage it. For waterbird populations, such studies can inform how 425 to manage populations at the centre of conflicts sustainably, in order to pursue the African-Eurasian 426 Waterbird Agreement (AEWA 2015). It is uncertain how the Islay case-study will develop in the 427 future following the UK's decision to leave the EU. Brexit could potentially lead to change in the 428 protection status of barnacle geese in the UK, however this could open up new options for the management of this conflict.

\section{ACKNOWLEDGEMENTS}

431 We are indebted to Rae McKenzie and others at SNH Islay for providing the survey data and fruitful discussions about the conflict. TM was supported by a Carnegie Trust for the Universities of Scotland grant awarded to NB, AK and SR (grant 50197).

\section{AUTHORS' CONTRIBUTIONS}

$435 \mathrm{NB}, \mathrm{AK}, \mathrm{SR}$ and TM formulated the question. TM conducted the analysis and wrote the paper. All 436 authors contributed to revisions.

\section{DATA ACCESSIBILITY}

438 The data used in this study are available from Dryad Digital Repository. 
Abraham, K.F., Jefferies, R.L. \& Alisauskas, R.T. (2005) The dynamics of landscape change and snow geese in mid-continent North America. Global Change Biology, 11, 841-855.

AEWA. (2015) Guidelines on Sustainable Harvest of Migratory Waterbirds. AEWA Conservation Guidelines No. 5, AEWA Technical Series No. 62. Bonn, Germany.

Bates, D., Maechler, M., Bolker, B. \& Walker, S. (2015) Fitting Linear Mixed-Effects Models Using lme4. Journal of Statistical Software, 67, 1-48.

Bunnefeld, N., Hoshino, E. \& Milner-Gulland, E.J. (2011) Management strategy evaluation: a powerful tool for conservation? Trends in Ecology \& Evolution, 26, 441-447.

Cope, D., Vickery, J. \& Rowcliffe, M. (2005) From conflict to coexistence: a case study of geese and agriculture in Scotland. People and wildlife, conflict or co-existence? (eds R. Woodroffe, S. Thirgood, \& A. Rabinowitz), pp. 176-191. Cambridge University Press, Cambridge, UK.

Dickey, M.-H., Gauthier, G. \& Cadieux, M.-C. (2008) Climatic effects on the breeding phenology and reproductive success of an arctic-nesting goose species. Global Change Biology, 14, 1973-1985.

Donald, P.F., Green, R.E. \& Heath, M.F. (2001) Agricultural intensification and the collapse of Europe's farmland bird populations. Proceedings of the Royal Society of London B: Biological Sciences, 268, 25-29.

Drechsler, M., Eppink, F. V. \& Wätzold, F. (2011) Does proactive biodiversity conservation save costs? Biodiversity and Conservation, 20, 1045-1055.

van Eerden, M.R., Drent, R.H., Stahl, J. \& Bakker, J.P. (2005) Connecting seas: western Palaearctic continental flyway for water birds in the perspective of changing land use and climate. Global Change Biology, 11, 894-908.

Elzhov, T., Mullen, K., Spiess, A.-N. \& Bolker, B. (2013) minpack.lm: R Interface to the LevenbergMarquardt Nonlinear Least-Squares Algorithm Found in MINPACK. R package version 1.1-8. 
Forslund, P. \& Larsson, K. (1992) Age-Related Reproductive Success in the Barnacle Goose. Journal of Animal Ecology, 61, 195.

Fox, A.D., Elmberg, J., Tombre, I.M. \& Hessel, R. (2016) Agriculture and herbivorous waterfowl: a review of the scientific basis for improved management. Biological Reviews.

Fox, A.D., Madsen, J., Boyd, H., Kuijken, E., Norriss, D.W., Tombre, I.M. \& Stroud, D.A. (2005) Effects of agricultural change on abundance, fitness components and distribution of two arcticnesting goose populations. Global Change Biology, 11, 881-893.

Gauthier, G., Giroux, J.-F., Reed, A., Bechet, A. \& Belanger, L. (2005) Interactions between land use, habitat use, and population increase in greater snow geese: what are the consequences for natural wetlands? Global Change Biology, 11, 856-868.

Henle, K., Alard, D., Clitherow, J., Cobb, P., Firbank, L., Kull, T., McCracken, D., Moritz, R.F.A., Niemelä, J., Rebane, M., Wascher, D., Watt, A. \& Young, J. (2008) Identifying and managing the conflicts between agriculture and biodiversity conservation in Europe-A review. Agriculture, Ecosystems \& Environment, 124, 60-71.

van der Jeugd, H.P. \& Larsson, K. (1998) Pre-breeding survival of barnacle geese Branta leucopsis in relation to fledgling characteristics. Journal of Animal Ecology, 67, 953-966.

Kahl, R. \& Samson, F. (1984) Factors affecting yield of winter wheat grazed by geese. Wildlife Society Bulletin, 12, 256-262.

Kirby, J.S., Stattersfield, A.J., Butchart, S.H.M., Evans, M.I., Grimmett, R.F.A., Jones, V.R., O’Sullivan, J., Tucker, G.M. \& Newton, I. (2008) Key conservation issues for migratory landand waterbird species on the world's major flyways. Bird Conservation International, 18, S49S73.

Lambert, R.A. (2015) Environmental history and conservation conflicts. Conflicts in conservation: Navigating towards solutions (eds S. Redpath, R. Gutiérrez, K. Wood, \& J. Young), pp. 49-60. Cambridge University Press, Cambridge, UK. 
Madsen, J., Williams, J.H., Johnson, F.A., Tombre, I.M., Dereliev, S. \& Kuijken, E. (2017) Implementation of the first adaptive management plan for a European migratory waterbird population: The case of the Svalbard pink-footed goose Anser brachyrhynchus. Ambio, 46, 275289.

McKenzie, R. \& Shaw, J.M. (2017) Reconciling competing values placed upon goose populations: The evolution of and experiences from the Islay Sustainable Goose Management Strategy. Ambio, 46, 198-209.

Menu, S., Gauthier, G. \& Reed, A. (2002) Changes in survival rates and population dynamics of greater snow geese over a 30-year period: implications for hunting regulations. Journal of Applied Ecology, 39, 91-102.

Michalski, F., Boulhosa, R.L.P., Faria, A. \& Peres, C.A. (2006) Human-wildlife conflicts in a fragmented Amazonian forest landscape: determinants of large felid depredation on livestock. Animal Conservation, 9, 179-188.

Mitchell, C. \& Hall, C. (2013) Greenland Barnacle Geese Branta Leucopsis in Britain and Ireland: Results of the International Census, Spring 2013. Wildfowl and Wetlands Trust, Slimbridge, UK.

Nakagawa, S. \& Schielzeth, H. (2013) A general and simple method for obtaining $R^{2}$ from generalized linear mixed-effects models. Methods in Ecology and Evolution, 4, 133-142.

Naughton-Treves, L. (1998) Predicting Patterns of Crop Damage by Wildlife around Kibale National Park, Uganda. Conservation Biology, 12, 156-168.

Owen, M. (1990) The damage-conservation interface illustrated by geese. Ibis, 132, 238-252.

Percival, S.M. \& Houston, D.C. (1992) The Effect of Winter Grazing by Barnacle Geese on Grassland Yields on Islay. Journal of Applied Ecology, 29, 35-40.

Pinheiro, J., Bates, D., DebRoy, S., Sarkar, D. \& R Core Team. (2016) Linear and Nonlinear Mixed Effects Models. R package version 3.1-125. 
R Core Team. (2016) R: A Language and Environment for Statistical Computing. R Foundation for Statistical Computing, Vienna, Austriia.

Redpath, S., Gutiérrez, R., Wood, K. \& Young, J. (2015) Conflicts in Conservation: Navigating towards Solutions. Cambridge University Press, Cambridge, UK.

Redpath, S. \& Sutherland, W. (2015) The value of ecological information in conservation conflict. Conflicts in conservation: Navigating towards solutions (eds S. Redpath, R. Gutiérrez, K. Wood, \& J. Young), pp. 35-45. Cambridge University Press, Cambridge, UK.

Redpath, S.M., Young, J., Evely, A., Adams, W.M., Sutherland, W.J., Whitehouse, A., Amar, A., Lambert, R.A., Linnell, J.D.C., Watt, A. \& Gutiérrez, R.J. (2013) Understanding and managing conservation conflicts. Trends in Ecology and Evolution, 28, 100-109.

Richards, S.A. (2015) Likelihood and model selection. Ecological statistics: Contemporary theory and application (eds G. Fox, S. Negrete-Yankelevich, \& V. Sosa), pp. 58-78. Oxford University Press, Oxford, UK.

Sedinger, J.S., Flint, P.L. \& Lindberg, M.S. (1995) Environmental Influence on Life-History Traits: Growth, Survival, and Fecundity in Black Brant (Branta Bernicla). Ecology, 76, 2404-2414.

Si, Y., Skidmore, A.K., Wang, T., De Boer, W.F., Toxopeus, A.G., Schlerf, M., Oudshoorn, M., Zwerver, S., Van der Jeugd, H.P., Exo, K.-M. \& Prins, H.H.T. (2011) Distribution of Barnacle Geese Branta leucopsis in relation to food resources distance to roosts and the location of refuges. Ardea, 99, 217-226.

Sillero-Zubiri, C., Sukumar, R. \& Treves, A. (2007) Living with wildlife: the roots of conflict and the solutions. Key Topics in Conservation Biology (eds D.W. Macdonald \& K. Service), pp. 253270. Blackwell Publishing Ltd, Oxford, UK.

Simonsen, C.E., Madsen, J., Tombre, I.M. \& Nabe-Nielsen, J. (2016) Is it worthwhile scaring geese to alleviate damage to crops? - An experimental study. Journal of Applied Ecology, 53, 916-924. 
Therkildsen, O.R. \& Madsen, J. (2000) Energetics of Feeding on Winter Wheat Versus Pasture Grasses: A Window of Opportunity for Winter Range Expansion in the pink-footed Goose Anser brachyrhynchus. Wildlife Biology, 6, 65-74.

Tombre, I.M., Eythórsson, E. \& Madsen, J. (2013) Towards a solution to the goose-agriculture conflict in North Norway, 1988-2012: the interplay between policy, stakeholder influence and goose population dynamics. PloS one, 8, e71912.

Treves, A., Naughton-Treves, L., Harper, E.K., Mladenoff, D.J., Rose, R.A., Sickley, T.A. \& Wydeven, A.P. (2004) Predicting Human-Carnivore Conflict: a Spatial Model Derived from 25 Years of Data on Wolf Predation on Livestock. Conservation Biology, 18, 114-125.

White, R.M., Fischer, A., Marshall, K., Travis, J.M.J., Webb, T.J., di Falco, S., Redpath, S.M. \& van der Wal, R. (2009) Developing an integrated conceptual framework to understand biodiversity conflicts. Land Use Policy, 26, 242-253.

Woodroffe, R., Thirgood, S. \& Rabinowitz, A. (2005) People and Wildlife, Conflict or Co-Existence? Cambridge University Press, Cambridge, UK.

Ydenberg, R.C. \& Prins, H.H.T. (1981) Spring Grazing and the Manipulation of Food Quality by Barnacle Geese. The Journal of Applied Ecology, 18, 443.

Young, J.C., Marzano, M., White, R.M., McCracken, D.I., Redpath, S.M., Carss, D.N., Quine, C.P. \& Watt, A.D. (2010) The emergence of biodiversity conflicts from biodiversity impacts: characteristics and management strategies. Biodiversity and Conservation, 19, 3973-3990.

Zuur, A.F., Ieno, E.N. \& Elphick, C.S. (2010) A protocol for data exploration to avoid common statistical problems. Methods in Ecology and Evolution, 1, 3-14. 


\section{Tables}

562 Table 1. Summary of model predictors, including the time-lags considered, the hypotheses they relate

563 to and their hypothesised effects on goose numbers.

\begin{tabular}{|c|c|c|c|c|c|c|}
\hline Analysis & Name & Description & Mean (range) & Time-lags & Hypothesis & Effect \\
\hline \multirow[t]{8}{*}{ Population-scale } & Grass Islay & Area of improved grassland on Islay & 7,040 ha $(5,331-8,331)$ & $t-1 ; t-2$ & 1 & + \\
\hline & Sheep $_{\text {Islay }}$ & Number of sheep on Islay & $65,913(47,040-78,537)$ & $t-1 ; t-2$ & 2 & - \\
\hline & Temp Islay $_{1}$ & Mean Islay October-March temperature & $5.0^{\circ} \mathrm{C}(3.5-6.5)$ & $t-1 ; t-2$ & 3 & + \\
\hline & Precip $_{\text {Islay }}$ & Total Islay October-March precipitation & $1,105 \mathrm{~mm}(829-1,462)$ & $t-1 ; t-2$ & 3 & - \\
\hline & Temp $_{\text {Aug }}$ & Mean August Greenland temperature & $2.9^{\circ} \mathrm{C}(1.1-5.2)$ & $t-1 ; t-2 ; t-3$ & 4 & + \\
\hline & Precip $_{\text {Aug }}$ & Total August Greenland precipitation & $16.6 \mathrm{~mm}(0.2-63.7)$ & $t-1 ; t-2 ; t-3$ & 4 & - \\
\hline & Temp $_{\text {May }}$ & Mean May Greenland temperature & $-6.4^{\circ} \mathrm{C}(-8.8--3.3)$ & $t-1 ; t-2 ; t-3$ & 4 & + \\
\hline & Precip May $_{\text {M }}$ & Total May Greenland precipitation & $6.2 \mathrm{~mm}(0-19.8)$ & $t-1 ; t-2 ; t-3$ & 4 & - \\
\hline \multirow[t]{3}{*}{ Stakeholder-scale } & Abund ${ }_{\text {Islay }}$ & Islay barnacle goose abundance & $41,400(28,500-53,000)$ & None & 5 & + \\
\hline & Grass $_{\text {Farm }}$ & Area of improved grassland on farm & 39.7ha (0-152.5ha) & None & 6 & + \\
\hline & Roost $_{\text {Farm }}$ & Distance to roost from farm & $4.6 \mathrm{~km}(0.2-13.9)$ & None & 7 & - \\
\hline
\end{tabular}


566 Table 2. Best models of farm-specific intercepts (a) and coefficients for the effect of Islay barnacle

567 goose abundance (b). Standardised coefficients, numbers of parameters (K), log-likelihoods (LL), $568 \Delta \mathrm{AIC}$ and $R^{2}$ are displayed. Null models are displayed for comparison, or in the case that they are the 569 most parsimonious. See Table 1 for descriptions of predictors.

a) Farm-specific intercept models

571

\begin{tabular}{r|cc|cc} 
& \multicolumn{2}{|c|}{ Occurrence } & \multicolumn{2}{c}{ Count } \\
\hline & Best & Null & Best & Null \\
\hline Grass $_{\text {Farm }}$ & $3.25 x^{0.66}$ & & 1.28 & \\
Roost $_{\text {Farm }}$ & $-5.34 x^{0.09}$ & & -0.89 & \\
$\mathbf{K}$ & 5 & 2 & 4 & 2 \\
LL & -158.36 & -219.58 & -263.80 & -268.34 \\
$\Delta \mathbf{A I C}$ & 0.00 & 116.44 & 0.00 & 5.09 \\
$\boldsymbol{R}^{2}$ & 0.69 & - & 0.09 & - \\
\hline
\end{tabular}

b) Farm-specific abundance coefficient models

\begin{tabular}{r|cc|c} 
& \multicolumn{2}{|c|}{ Occurrence } & Count \\
\hline & Best & Null & Null \\
\hline Grass $_{\text {Farm }}$ & -0.15 & & \\
Roost $_{\text {Farm }}$ & $1.34 x^{0.16}$ & & \\
$\mathbf{K}$ & 4 & 2 & 2 \\
LL & -61.02 & -72.28 & -251.18 \\
$\Delta \mathbf{A I C}$ & 0.00 & 18.52 & 0.00 \\
$\boldsymbol{R}^{2}$ & 0.19 & - & - \\
\hline
\end{tabular}


Figure 1. The distribution and abundance of Greenland barnacle geese across their range (a) and on Islay, including distributions of roosting sites (b). Goose abundances at wintering sites were calculated using Wildfowl and Wetlands Trust survey data (Mitchell \& Hall 2013). Goose density per hectare of farmland on Islay was calculated using Scottish Natural Heritage survey data.

Figure 2. Annual variation in barnacle goose mean abundance on Islay (a), area of improved grassland on Islay (b), number of sheep on Islay (c) and temperature on Islay and Greenland (d). season.

Figure 3. Standardised coefficients $\pm 95 \%$ confidence intervals for the best model of Islay barnacle goose abundance, according to AIC. See Table 1 for descriptions of predictors.

Figure 4. Partial effects of selected environmental predictors on Islay barnacle goose abundance. $R^{2}$ displayed for each partial effect. See Table 1 for descriptions of predictors.

Figure 5. Fitted effects of Islay barnacle goose abundance on farm-scale barnacle goose probability of occurrence (a) and number (b), from best occurrence and count models. Shaded areas represent fitted values \pm standard errors. Models were fitted for an average farm, with day set to an intermediate level ( $5^{\text {th }}$ December).

Figure 6. Fitted effects of mean area of improved grassland and distance to nearest roosting site on farm-scale barnacle goose probability of occurrence (a-b) and number (c-d). Points are farm-specific estimates from the best occurrence and count models. Lines are produced by incorporating the relationships between farm-specific intercepts and grassland/distance to roost (see Table 2a) into the fitted estimates. Models were fitted with abundance and day set to intermediate levels $\left(4,000 ; 5^{\text {th }}\right.$ December).

Figure 7. Percentage change in farm-scale probability of barnacle goose occurrence with Islay goose abundance, for farms with varying improved grassland area (a) and proximity to roosting site (b). 
600 Fitted lines are produced by incorporating the relationships between farm-specific intercepts/slopes 601 and grassland/distance to roost (see Table 2) into the fitted estimates of the best occurrence model. 602 Models were fitted with day set to an intermediate level ( $5^{\text {th }}$ December). 
605 Additional Supporting Information may be found in the online version of this article:

606 Table S1. Population-scale model selection table.

607 Table S2. Farm-scale model selection table.

608 Fig. S1. Relative timings of variables.

609 Fig. S2. Temporal trends in climatic variables.

610 Fig. S3. Influence of day on farm-scale goose numbers. 
a)

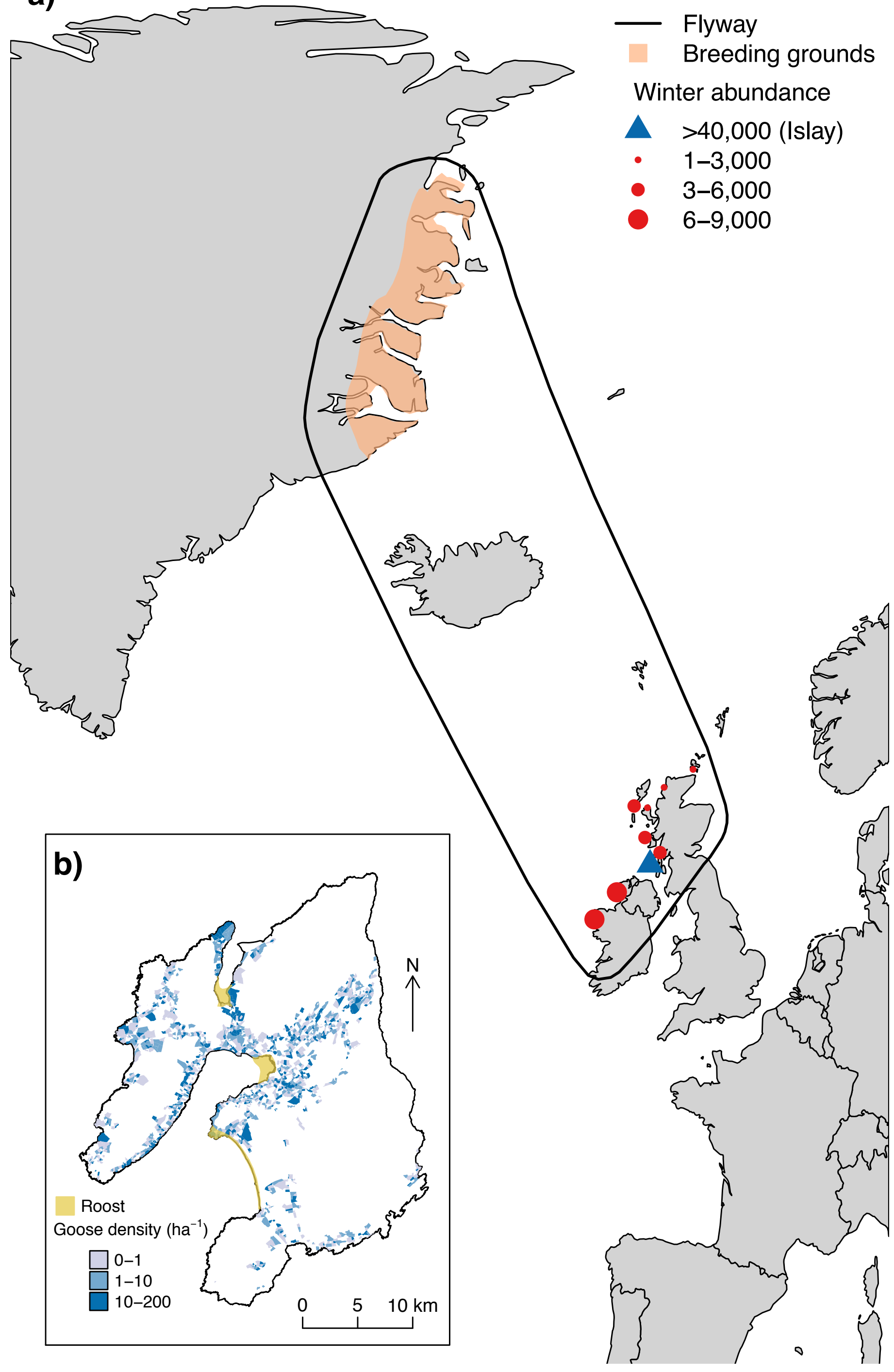



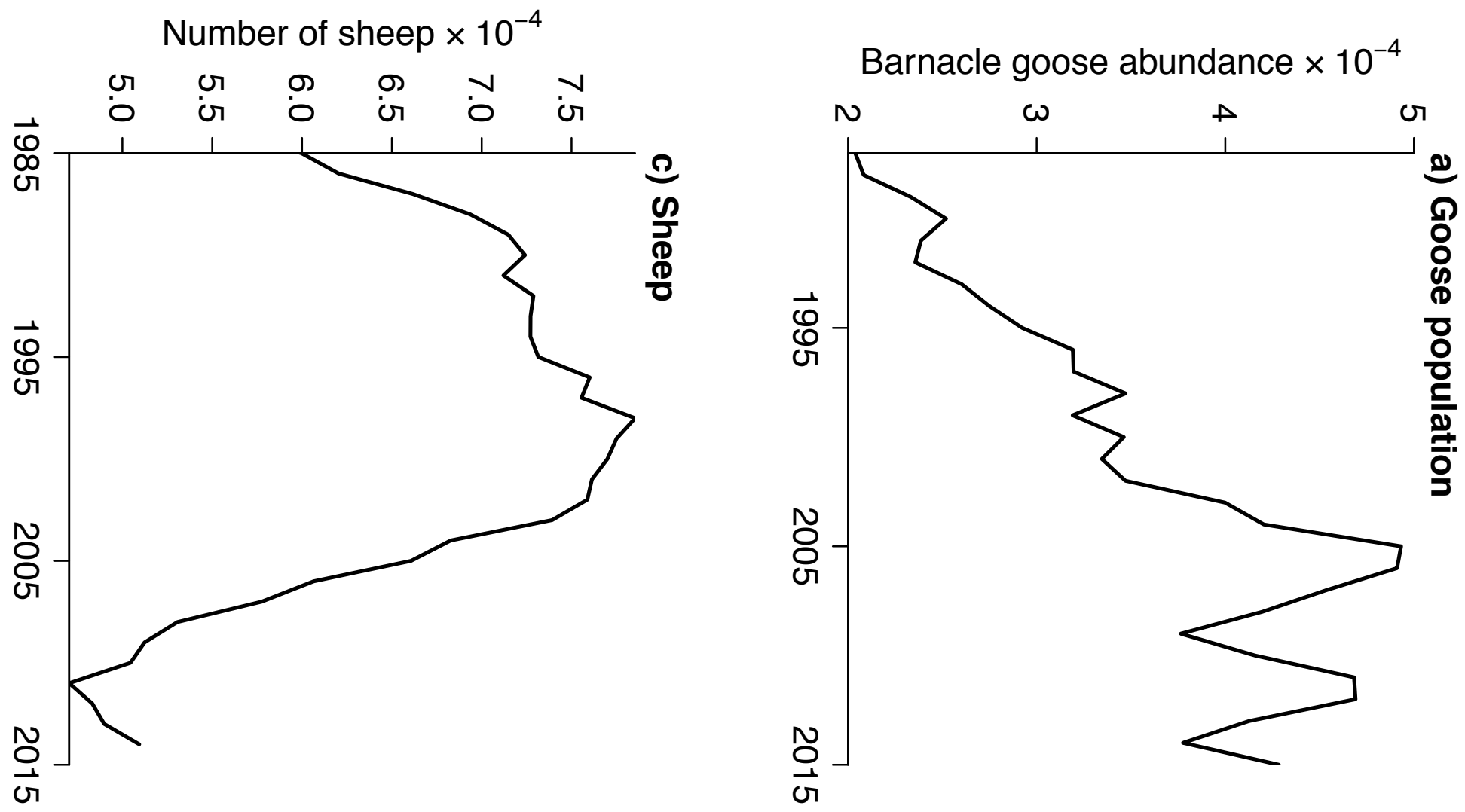

న

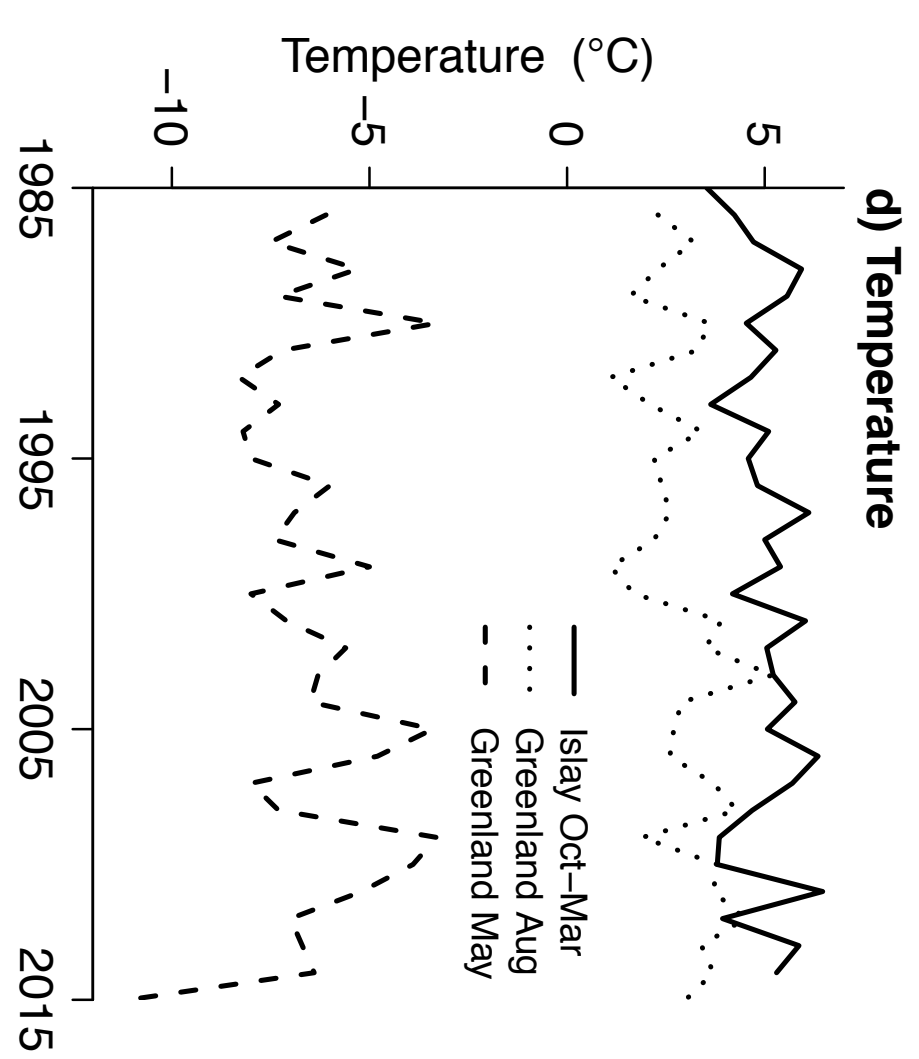

Area of improved grassland $\times 10^{-3}$

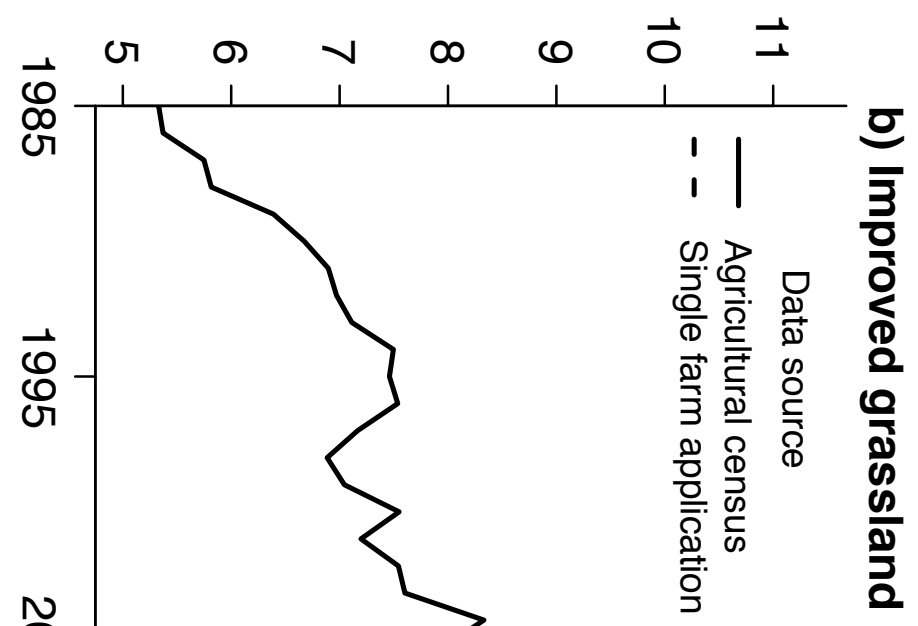

ơ 


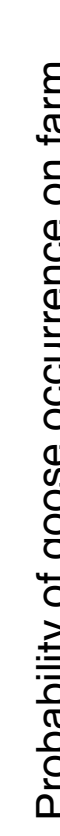

a)

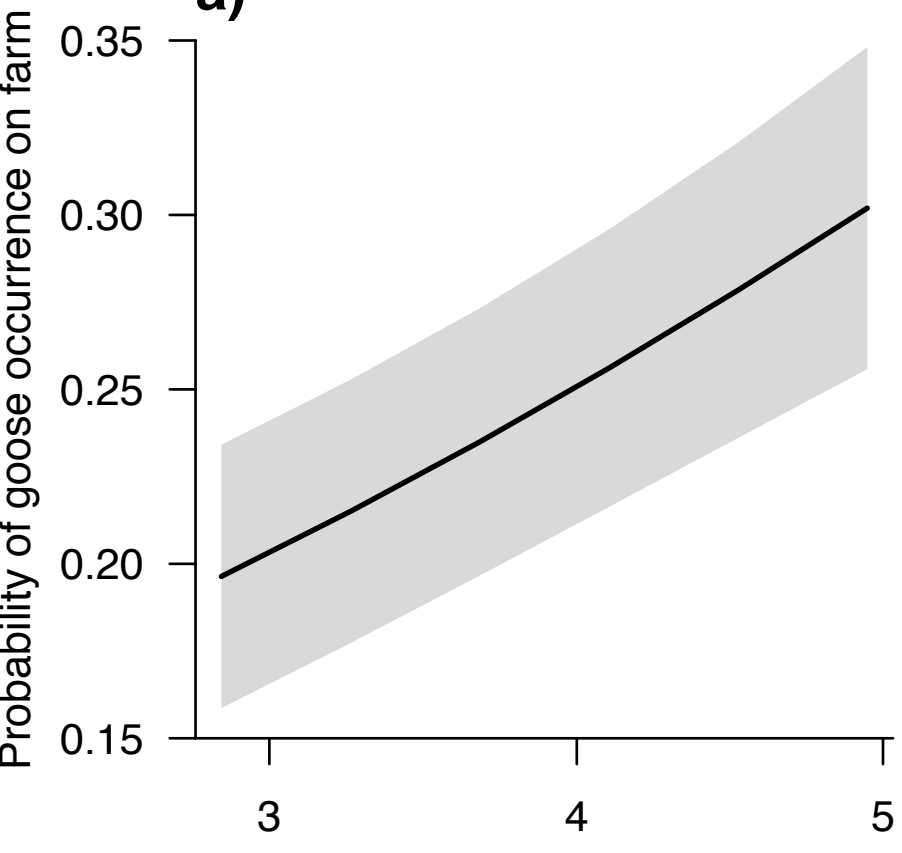

b)

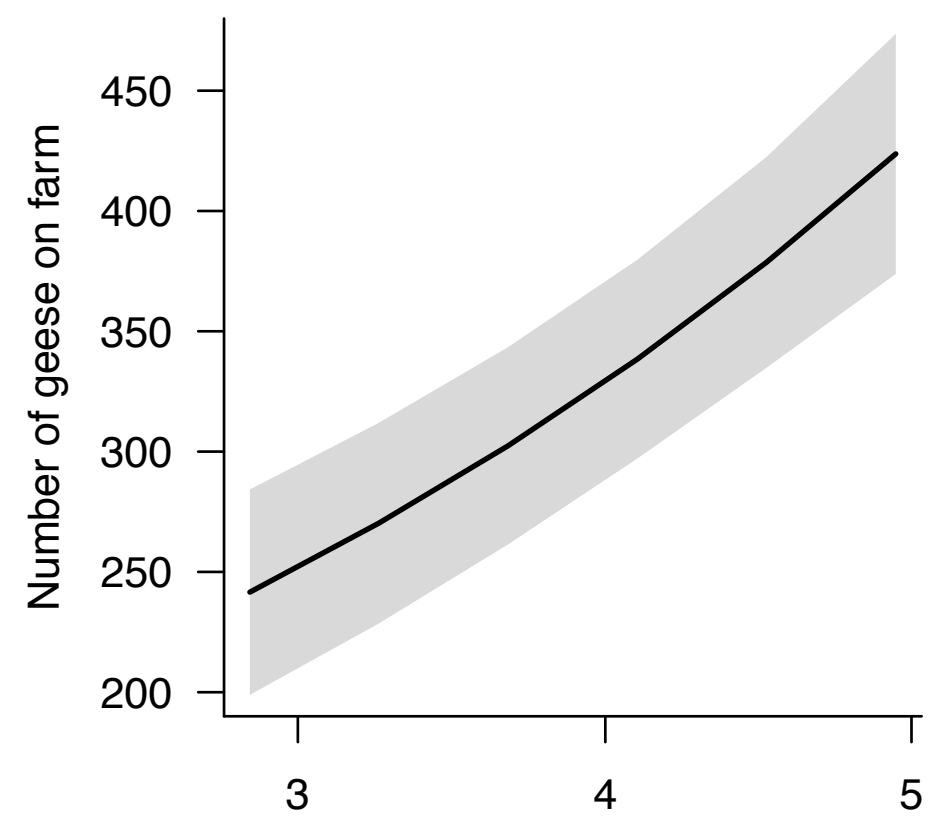

Islay barnacle goose abundance $\times 10^{-4}$ 


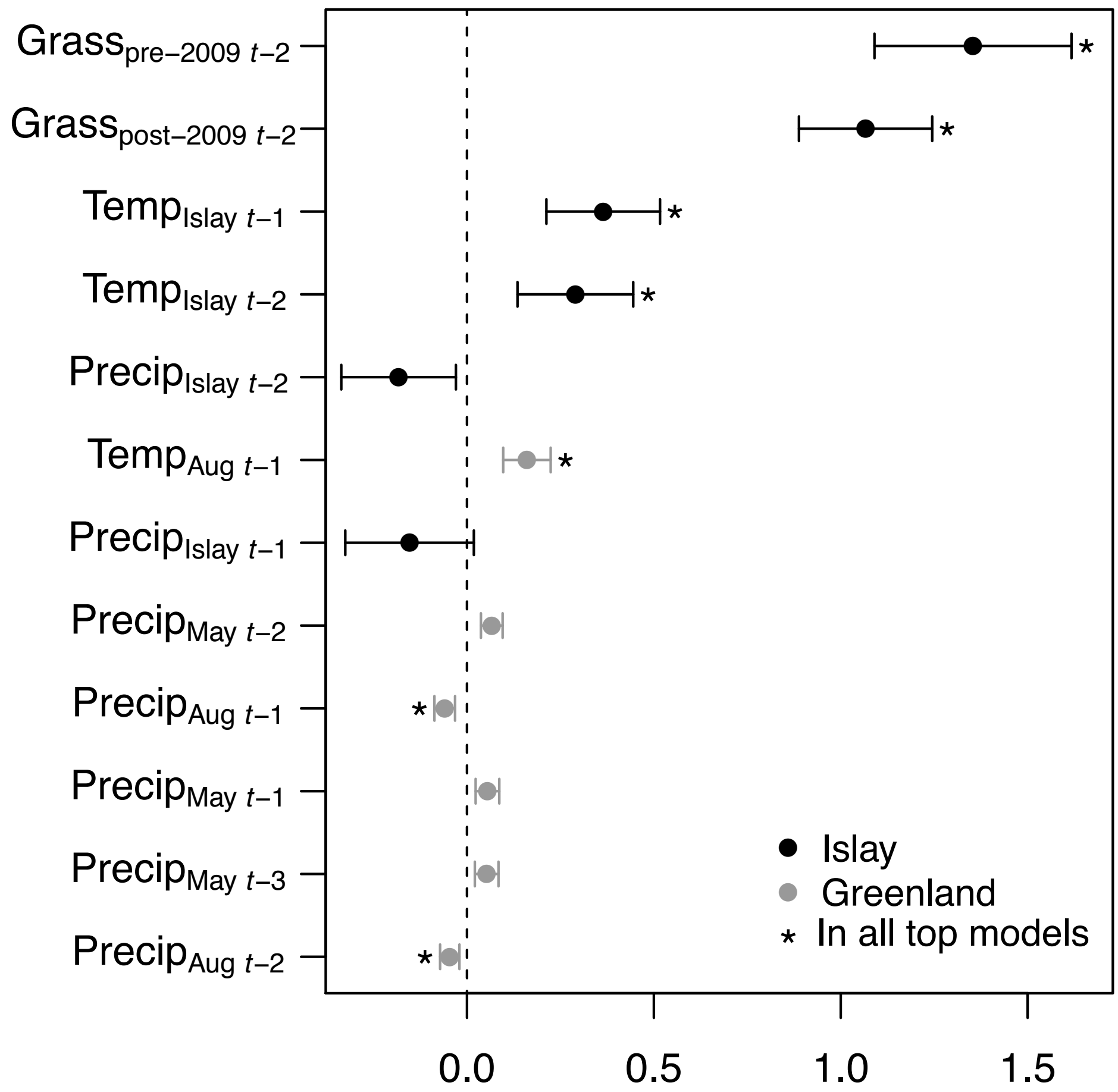

Standardised coefficient 

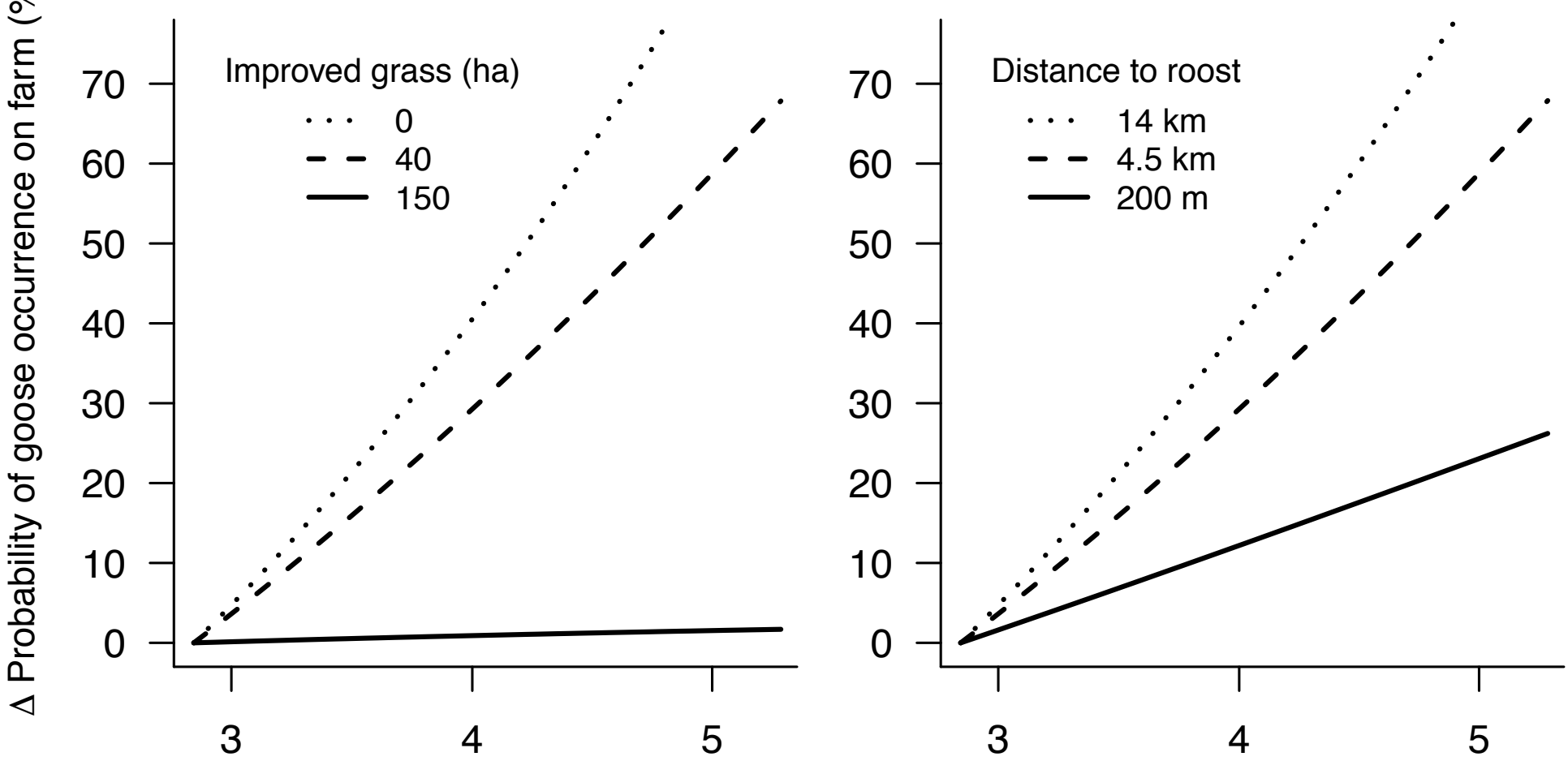

Islay barnacle goose abundance $\times 10^{-4}$ 

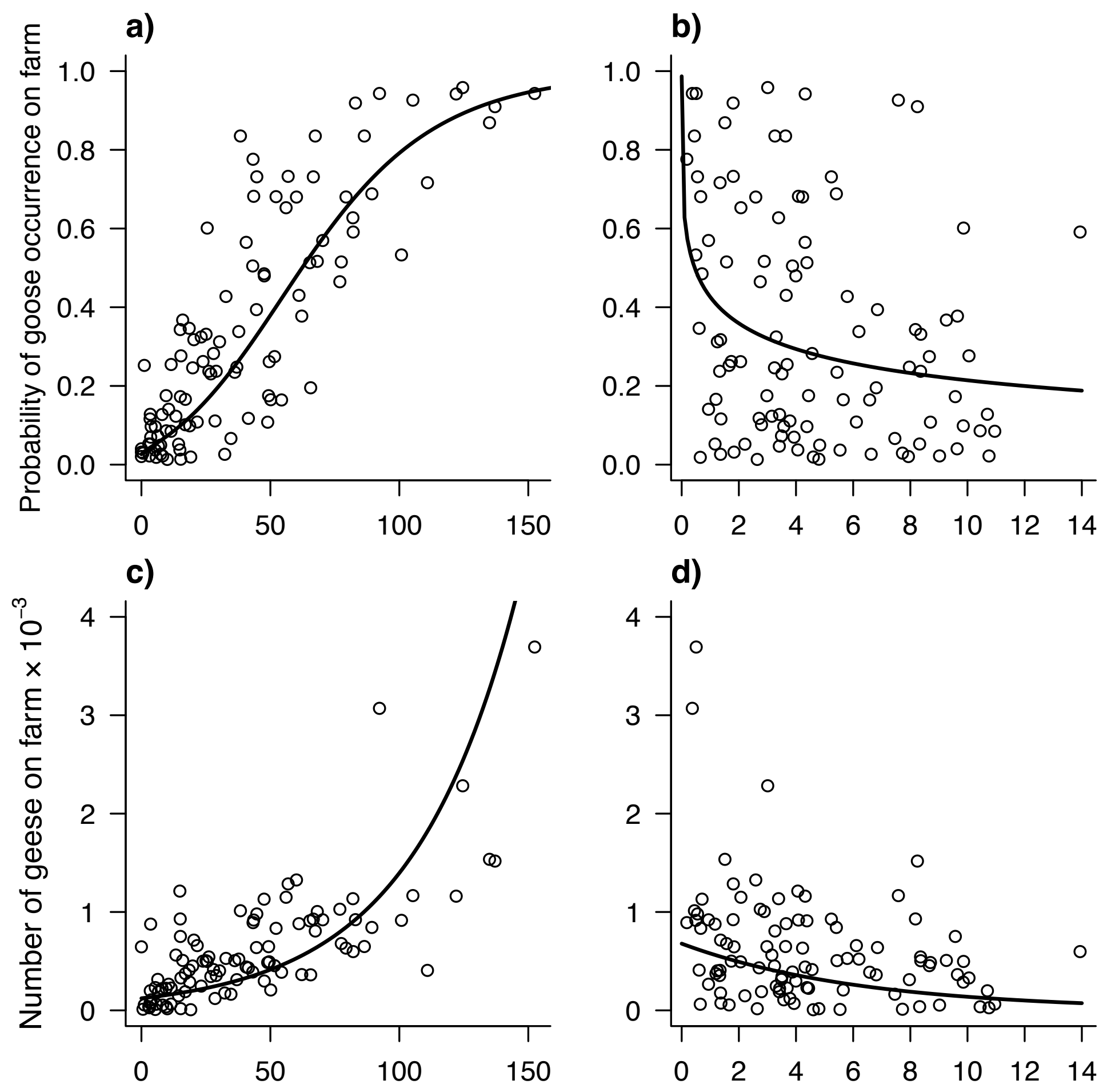

Mean area of improved grassland (ha) Distance to nearest roost $(\mathrm{km})$ 